\title{
Features of oil production and complications of Mesozoic deposits operation (on the example of the Grozny oil region)
}

\author{
Elmurzayev A.A. \\ Department of Technological Machines and Equipment \\ Institute of Oil and Gas \\ Grozny State Oil Technical University named after academician \\ M.D. Millionshchikov \\ Grozny, Russia \\ Ayub_777@mail.ru
}

Aliyev I.I.

Department of Drilling, Development and Operation of Oil and Gas Fields

Institute of Oil and Gas

Grozny State Oil Technical University named after academician M.D. Millionshchikov

Grozny, Russia

Abr1377@gmail.com

\author{
Khaladov A.Sh. \\ Department of Drilling, Development and Operation of Oil and \\ Gas Fields \\ Institute of Oil and Gas \\ Grozny State Oil Technical University named after academician \\ M.D. Millionshchikov \\ Grozny, Russia \\ haladov_a sh@mail.ru
}

Tsamayeva P.S.

Department of Technological Machines and Equipment Institute of Oil and Gas

Grozny State Oil Technical University named after academician M.D. Millionshchikov

Grozny, Russia

pstsam@mail.ru

\author{
Dudaev M.M. \\ Department of Drilling, Development and Operation of Oil and Gas Fields \\ Institute of Oil and Gas \\ Grozny State Oil Technical University named after academician M.D. Millionshchikov \\ Grozny, Russia \\ mongp-2013@mail.ru
}

\begin{abstract}
The main mechanism of oil displacement is characterized by gradual vertical movement of oil-water contact with insulation of watering out intervals in production wells. Different compositions on the basis of hydrochloric acid are traditionally used as working fluids to increase the formation pressure. The use of mud acid representing the mix of hydrochloric and fluoric acids gives the maximum effect.
\end{abstract}

Keywords-field, oil-bearing capacity, formation pressure, solutions, emulsions, oil and gas pipelines, corrosion, inhibitors.

\section{INTRODUCTION}

The current state of oil industry requires urgent solution of fundamental tasks.

In many respects, the use of different methods to influence the productive layers and their efficiency is defined by geological features of the oil and gas field. The main hydrocarbon fields are characterized by specific features. They belong to strongly faulted linearly elongated anticlines of eastwest trending. The average linear sizes make $4-6$ x 25-35 km, the amplitude - from 600 to $1100 \mathrm{~m}$. Morphologically the faults are expressed almost along the entire section of MesoCenozoic deposits. The structures are mainly expressed in cretaceous deposits, including large and average massive and sheet-like oil and gas deposits. In particular, the Upper Cretaceous oil deposits are bound to fractured and fracturedcavernous carbonate reservoirs. The western submerged part of the region is characterized by mixed fractured reservoirs. The fractured reservoirs, which porosity is defined by cavities, are typical for submerged eastern parts of the region.

\section{METHODS AND MATERIALS}

Based on the main provisions of modern petroleum science, the reserves estimate and design shall be performed taking into account geological, on-balance, off-balance and recoverable reserves. Geological models shall be designed on the basis of conceptually new principles taking into account these categories, while the filtration models shall be built taking into account the contemporary views on filtration processes. Planning shall be made on the basis of hydrocarbon 
pore volume (HPV) using models that consider geological reserves, all features of the geological structure of deposits, development principles of innovative design taking into account new optimality and rationality criteria [1].

It is known from various sources that according to core tests, the total porosity of reservoirs of the Upper Cretaceous ranges from 1.5 to $20 \%$ (its average makes $2-5 \%$ ). Their fracture porosity makes approximately $0.2-0.5 \%$, cavernous porosity $-0.1-3.0 \%$. Permeability of a limestone on a surface is low, it is not dependent on porosity. The Upper Cretaceous productive layer is characterized by abnormally high formation pressure (AHFP), high formation temperature (155$\left.185^{\circ} \mathrm{C}\right)$, considerable gas saturation $\left(450-850 \mathrm{~m}^{3} / \mathrm{t}\right)$, low viscosity of reservoir oil [2]. The results of hydrodynamic and other studies showed that the fractured reservoirs are characterized by sharp inhomogeneity of permeability by thickness and extension, which in some cases is the main reason of low productivity of wells [3].

The stimulation of oil production in such deposits is mainly carried out by chemical simulation of the formation. Various compositions on the basis of hydrochloric acid are used as working fluids. The data analysis shows that the efficiency of chemical treatment is low and tends to further reduction. One of the reasons of low efficiency of acid treatment is the unevenness of the working fluid absorption along the formation thickness. Acid mainly gets into zones of increased permeability, and low-permeability oil-saturated zones are not exposed to chemical influence [4]. Besides, the decrease in treatment efficiency of low-permeability zones is bound to secondary sedimentation caused by the deposition of insoluble compounds of trivalent iron in the formation after acid removal. For many years, hydrochloric treatment or treatment with hydrophobic emulsified acid was the only way of bottomhole zone treatment. The technology of acid treatment included the preparation of $12-15 \%$ solution of hydrochloric acid, its injection into the well and pumping through the formation with oil or water during time sufficient for acid removal with subsequent inflow stimulation [5]. In some cases, upon pumping through, the acid was left in the formation for $0.5-2$ hours for complete removal and then the well was put into operation. The treatment with hydrophobic emulsified acid was carried out according to a similar scheme. Hydrophobic emulsified acid represents structured systems containing acid, hydrocarbon phases and emulsion stabilizer. Diluted hydrochloric acid is used as an acid phase and light crude, kerosene or diesel fuel is used as a hydrocarbon phase. Aliphatic amines mainly serve as the stabilizers of hydrophobic emulsified acid [6].

The treatment of deep Mesozoic wells of Grozneftegaz with hydrochloric acid and hydrophobic emulsified acid shows quite low efficiency. Low efficiency of formation treatment with salt-acid emulsions is caused by a variety of reasons, in particular, unevenness of acid flow distribution along the thickness of the treated interval. When injected into heterogeneous formation the acid mainly gets into highpermeability intervals.

Another reason of low efficiency of salt-acid treatment is sharp reduction of hydrochloric acid removal period in the formation with the growth of formation temperature and increase in its corrosion activity.

High efficiency of salt-acid treatment at the first stage of the considered period is explained by a big share of primary treatment during well development after drilling. In this case, even at a small formation depth the treatment causes a positive effect due to bottom-hole treatment of the formation after drilling.

The use of hydrophobic emulsified acid allowed increasing the efficiency of treatment, especially at the initial stage of development of Mesozoic oil deposits. This is explained by the increase of the depth of chemical treatment at relatively small most permeable intervals of the penetrated formation section in comparison with salt-acid treatment [3].

In general, the use of hydrophobic emulsified acid in deep wells is more efficient than the salt-acid treatment. The common disadvantage of salt-acid solutions and compositions on their basis is the sharp decrease in treatment efficiency at the temperatures above $80-100^{\circ} \mathrm{C}$ due to the increase in acid removal speed in the formation and considerable growth of corrosion of the downhole equipment.

The analysis of domestic and foreign experience shows that the use of these solutions, especially in deep wells, is not always positive. For example, in deep Mesozoic wells of Grozneftegaz the treatment efficiency of the bottomhole formation zone with acid solutions makes on average $50 \%$ and with hydrophobic emulsified acid on their basis $-66.6 \%$. The increase of the depth of productive deposits leads to the decrease of treatment efficiency. This is mainly caused by natural deterioration of reservoir porosity and permeability, growth of the depth of rock bedding and increase of formation pressure and temperature. Thus, this leads to fast acid removal in close proximity to a bottom hole and to shale hydration in neutralized solutions causing the decrease in reservoir permeability. All this complicates good hydrodynamic relation of a bottom hole with the formation.

The variability of reservoir properties along thick formation section is the reason of absorption of acid agents mainly by high-permeability intervals while low-permeability zones are almost not exposed to treatment. In some cases, this leads to sharp increase in water content of extracted products. Low efficiency of traditional treatment methods in the conditions of deep reservoirs with high pressure and temperature causes the need to improve the already known and to develop new technological treatment methods, which at the reduction of corrosion failure of downhole equipment would ensure the considerable increase in well productivity and improvement of reservoir properties of the bottomhole zone [4].

It is established that the treatment efficiency is defined by the penetration radius of the working agent in its chemically active state deep into the formation, amount of dissolved rock, influence of reaction products on permeability and corrosion failure of downhole equipment. At present, acids or their mixes, as well as substances forming the acids able to dissolve a sandstone are used for stimulation of oil production from aleurolite-siltstone deposits. The use of mud acid representing 
the mix of hydrochloric and fluoric acids gives the most positive effect. Initially it was used to remove the clay cake from the wellbore walls, and then it was also successfully used to dissolve rocks within a formation. The mud acid allowed sharply increasing the efficiency of chemical treatment on aleurolite-siltstone productive deposits. This is ensured by the ability of the fluoric acid added into the solution to react well with quartz, clay and calcite present in a sandstone. The field operations showed higher efficiency of mud-acid treatment in comparison with the salt-acid one $[5,6]$. The addition of methyl alcohol into mud-acid solutions also decreases the surface tension on a phase boundary [4]. It creates favorable conditions for treatment and drying of the formation from water, reaction products and other impurities [3].

The injection of acid solution into the formation is followed by its dilution with water thus leading to the decrease in the concentration of reacting substances. Besides, fluoric acid is partially neutralized by salts contained in formation water. These processes reduce the solvent ability of acid. As shown in work [7], with the increase of water saturation of rocks up to $25-40 \%$ the rate of increase in porosity and permeability sharply decreases when the acid solution is injected into the rock. These studies result in the conclusion that at water saturation of more than $50 \%$ it is not inexpedient to perform acid treatment of the formation bottomhole zone. In this regard in order to increase the efficiency of operations related to stimulation of oil and gas production it is suggested to increase the concentration of acid taking into account the formation water saturation. The simplicity of technology that implies the use of mud acid and relative availability of reagents causes its broad application even in difficult miningand-geological conditions. However, high formation thickness and low volume velocity of acid injection lead to its fast removal.

Concentrated acid solutions are more preferable for treatment of deep-laying fractured and fractured-porous reservoirs. The industry delivers fluoric acid in the concentration of $40 \%$ and inhibited V-2 hydrochloric acid in the concentration of up to $24 \%$. It is possible to prepare the solution with the maximum content of fluoric acid $-10 \%$ and hydrochloric acid - 23\% from these acids. With such composition, the solution can dissolve up to $460 \mathrm{~kg}$ of rock in $1 \mathrm{~m}^{3}$ of a mix.

However, fluoric acid is toxic, scarce, its transportation requires a special container; it is difficult to prepare a working solution from it.

Besides high speed of acid removal, there is a considerable corrosion wear of downhole equipment at high temperatures. In the conditions of big depths, it results in the need to replace the tubing string after 3-4 treatments, which causes the need for well killing, workover and subsequent development. Emulsification in hydrocarbon phase is widely used in the world to increase the penetration depth of acid in its chemically active state into the formation and to protect the downhole equipment [3]. The use of hydrophobic emulsions along with the reduction of corrosion failure of downhole equipment provided for considerable treatment efficiency of high-temperature productive deposits. Possessing a certain storage stability, the acid emulsion begins to decay at some distance from a well bottom, and the emitted acid reacts with the rock. This method of acid delivery ensures the creation of high capacity filtration channels, which get deep into the formation.

However, the hydrophobic acid emulsion mainly gets into high-permeability intervals. Then, the decomposition of acid emulsion leads to sharp decrease of its viscosity thus contributing to subsequent portions of injected fluid to the same filtration channels increasing their permeability even more. At the same time, low-permeability zones are almost not exposed to chemical treatment. This limits the possibility of increasing well productivity, leads to the increase of formation inhomogeneity regarding permeability, can ensure premature flooding of well products. Another reason of treatment efficiency decrease is sharp reduction of stability of emulsions caused by the temperature increase [9].

At present, there are multiple methods to stimulate oil and gas production, which, instead of chloride hydrogen in a working solution, use other acids, for example, sulphamic [10], sulfuric, phosphoric acid or its salts. The treatment in some domestic and foreign fields shows their high efficiency, however these methods failed to find their wide application.

In fact, hydraulic fracturing of the Upper Cretaceous deposits did not get beyond the area of the experiment and was applied partially. Operation of deep wells becomes especially complicated at the last development stage when considerable amount of water is produced together with oil. Due to heterogeneity of the geological structure the formation waters blow out into wells along the most permeable zones of the formation [11]. The studies show that only separate intervals with relatively high permeability amounting to $7-30 \%$ of the penetrated formation thickness usually participate in filtration near a well wall. Water from other stratigraphic horizons gets into wells due to frequent cases of low-quality formation isolation at big depths. Water inflow into wells reduces oil production and requires the solution of difficult tasks related to collection, transportation and treatment of oil, protection of oil-field equipment against corrosion, etc., which deteriorates technical and economic indicators of reservoir management. Therefore, the task of water suppression in deep wells that drain fractured and fractured-porous formations is quite relevant [12].

\section{RESULTS}

The petroleum industry uses various methods to reduce the water encroachment based on the injection of cement mortars, sediment forming chemical reagents and polymerized substances into the bottomhole zone of the formation. One of the most widely used methods of water encroachment in the conditions of fractured formations is the isolation of the drained interval by installing a cement plug with subsequent transition to the overlying object. The efficiency of cement plugs was not so high and for example, in Grozneftegaz made $40-45 \%$. The method is complex, labor consuming and expensive. The works often take a few months, costs for each well operation are high. It shall be noted that when cement mortars and polymerized substances are used for water 
encroachment, the productivity of oil wells decreases due to irreversible damage of the bottom-hole zone permeability [8].

There are methods of selective water shutoff using oilsoluble isolating materials (naphthalene, gilsonite, etc.), sediment forming reagents (for example, aqueous polymer solutions), etc. In the conditions of Mesozoic deposits of the Chechen Republic the thermoplastic polymers from the polyolefins group - high-density polyethylene (HDPE), commercial flow polymer (CFP), and gasoline flow polymer (PPS) were used for selective water shutoff [13].

High-density polyethylene represents a high-molecular polymineralization product of ethylene with the density of $945-955 \mathrm{~kg} / \mathrm{m}^{3}$. Its melting temperature is $120-125^{\circ} \mathrm{C}$. It is produced in the form of powder or granules of $2.0-4.0 \mathrm{~mm}$ in size. Commercial flow polymer is produced in porous bastlike pieces of various size. The density of commercial flow polymer makes $900-920 \mathrm{~kg} / \mathrm{m}^{3}$. Its melting temperature is $115-$ $120^{\circ} \mathrm{C}$. Gasoline flow polymer is delivered in the form of a waxy mass. Its density makes about $900 \mathrm{~kg} / \mathrm{m}^{3}$. Gasoline flow polymer has no accurately expressed melting point and shifts into a fusion at about $100^{\circ} \mathrm{C}$. The treatment efficiency with polyolefins in Grozneft makes on average $60 \%$.

It is established that due to insufficient solubility of polymers in oil at formation temperature lower than the melting temperature the treatment with polyolefins may lead to the reduction of permeability of oil-saturated zones and the decrease of oil flow rate. In some cases, they are withdrawn from the formation after a well is put in operation and complicate the operation of wellhead equipment and oil-andgas-gathering systems [4].

To improve the efficiency of selective water shutoff the highly oxidized bitumen is studied as an isolating material. The study of rheological properties of bitumen of X-1 brand and rubrax A and B made it possible to establish high shear yield point and viscosity, which allows creating stable water isolating screens at formation temperatures of $160^{\circ} \mathrm{C}$ and differential pressure of up to $20 \mathrm{MPa}$. The qualitative isolating partition is formed in the flooded intervals of the formation due to adhesive properties of bitumen, its ability to be deformed and aggregated at increased temperatures. The methods of isolation and water encroachment using cement mortars and bitumen became the most popular [7, 12].

Besides problems with extraction of hydrocarbon raw materials there are other serious problems in oil and gas industry. One of them is lack of investments, which prevents drilling contractors to renew their equipment systematically. The last quarter of the century the Russian drilling companies mainly used drilling rigs produced in the Soviet times. Even the largest companies, which bought new equipment, currently have more than $50 \%$ of the Soviet facilities. The last mass release of domestic drilling rigs was in 1987-1990s. Considering the fact that the maximum authorized operation period of a facility is 25 years, the companies expect the mass write-off of drilling rigs being on their balance. Depending on investments over those years from 50 to $100 \%$ of the equipment fleet shall be written-off. This causes the problems of integrity of process equipment and its effective use [14].
At present, due to changing operation and production conditions (production drawdown, reduction of flow rates, deficiency and phase-out of earlier recommended corrosion inhibitors, as well as due to wear of pipelines), the internal corrosion and loss of pipeline sealing (ruptures, weld holes) still take place despite the implemented protective measures. In 1988-1999s, the pipeline network of oil-and-gas collecting systems of Grozneft was studied. The operation mode contributing to (corrosive) or preventing (anticorrosive) the release of formation water into a free phase contacting the metal of a bore surface was defined for each analyzed site of oil-and-gas pipeline, depending on its extent, diameter, liquid flow rate, average transportation pressure, water content and gas saturation of oil. As a result, $14469 \mathrm{~km}$ of oil-and-gas pipelines operating in anticorrosive mode were identified [8].

However, the increase in water content of transported products with simultaneous decrease in its gas saturation should inevitably affect the loading and the operation modes of these oil-and-gas pipelines. The mode on its certain sites should change from anticorrosive to corrosive. The current corrosion state of oil-and-gas pipelines was estimated by the comparison of rupture frequencies over two periods: earlier analyzed and currently analyzed.

The current corrosion state of water passageways of all fields was analyzed through their reliability index using statistical analysis of the current corrosion destruction of passageways (ruptures, weld holes) followed by flood or leakage of transported products. In general, three methods are used to protect metals against corrosion in industrial practice:

1. Isolation of metal surface from corrosion environment.

2. Decontaminating treatment of environment reducing its corrosion.

3. Maintenance of such energy condition of a metal, at which its thermodynamic oxidation is impossible or is extremely slow.

Now technological and inhibitory protection is used in Grozneft to protect the inner pipeline surface against corrosion and maintain the formation pressure [15].

The efficiency of technological protection of oil-and-gas pipelines of each field can be assessed according to the total length of their pipeline network in operation in the anticorrosive mode:

- $\quad$ Hayan-Kort field - 9.7 km (100\% efficiency);

- Pravoberezhnoye field - $49.05 \quad \mathrm{~km} \quad(86.2 \%$ efficiency);

- Severo-Bragunskoye field - $38.5 \mathrm{~km}$ (99.7\% efficiency);

- Oktyabrskoye field - $4.0 \mathrm{~km}$ (96.4\% efficiency);

- Khankala field $-2.4 \mathrm{~km}$ (100\% efficiency).

\section{CONCLUSIONS}

Thus, the analysis of the current corrosion condition of $908.9 \mathrm{~km}$ of oil-and-gas pipelines and $516.4 \mathrm{~km}$ of passageways revealed pipelines with satisfactory and unsatisfactory corrosion condition and allowed assessing the 
damage caused to the environment due to the loss of sealing, efficiency of inhibitory protection of oil-and-gas pipelines and passageways, extent of its influence on tactical frequency of pipeline ruptures and made it possible to establish that the inhibitory protection of oil-and-gas pipelines and passageways in Grozneft can be considered effective.

\section{References}

[1] R.Kh. Muslimov, "Fundamental problems of oil industry development," Journal of Petroleum Industry, No. 1, pp. 6-11, 2017.

[2] A.A. Daukayev, M.B. Muskhadzhiyev, "Geological features of oil and gas fields of the Chechen Republic in connection with problems of their further development using secondary and tertiary methods," Materials of the I international scientific and practical conference. Bulatov's readings Vol. 3, pp. 310-312, 2017.

[3] A.Sh. Khaladov, "Geological field characteristic and oil recovery of mesozoic oil deposits in the Chechen Republic," Materials of the international youth scientific conference "High Technologies in the Solution of Oil and Gas Problems", pp. 324, 2016.

[4] N.M. Degtyarev, et al., Assessment of prospects and results of increasing oil recovery of mesozoic deposits of the Chechen Republic: Materials of the All-Russian scientific and practical conference. Grozny: Academy of Sciences of the Chechen Republic, pp. 57-70, 2012.

[5] L.Kh. Kadyrov, "Analysis of flooding of Mesozoic deposits of the Chechen Republic subjected to anthropogenic impact," Journal of Petroleum Industry, No. 1, 2010.
[6] G.S. Dubinsky, "Geological and technological justification of target methods to increase oil recovery and ensure water suppression in highviscosity oil deposits," Problems of collection, preparation and transport of oil and oil products, No. 2 (92), pp. 5-15, 2013.

[7] V.P. Bondarenko, K.S. Nadirov, V.G. Golubev, A.S. Kolesnikov, A.S Sadyrbaeva, "Study of properties of oil-water inverse emulsions used for killing wells," Journal of Petroleum Industry, pp. 22-27, No. 1, 2017.

[8] I.A. Kerimov, E.M. Aksenov, Mineral raw material resources of the Chechen Republic: monograph. Grozny: Groznensky Rabochy Publishing and Printing Complex, 2015.

[9] I.A. Kerimov, A.A. Daukayev, T.H. Bachayeva, "Modern prospects of oil-and-gas content of cretaceous complex of Tersko-Caspin fold," Bulletin of the Chechen Academy of Sciences, No. 1, pp. 75-79, 2010.

[10] E.N. Trofimova, E.V. Artyushkina, O.A. Bykova, "On the deformation of rocks," Journal of Petroleum Industry, No. 8, pp. 10-13, 2018.

[11] P.I. Zabrodin, N.D. Rakovsky, M.D. Rozenderg, Replacement of oil from layer with solvents, M.: Nedra, 1998.

[12] V.A. Sidorovsky, Formation drilling and increasing well efficiency, M.: Nedra, 1998.

[13] A.A. Glazkov, F.N. Marichev, "On the possibility of using sulfamic acid for treating terrigenous reservoirs," Oil Field Business, No. 7, pp. 35-38, 1990 .

[14] G.I. Shmal, "Oil and gas complex in the context of geopolitical and economic challenges: problems and solutions," Journal of Petroleum Industry, No. 5, pp. 34-38, 2017.

[15] M.A. Saidov, P.S. Tsamayeva, A.A. Elmurzayev, "Study of corrosive influence of hydrogen sulfide on industrial equipment." Works of $\mathrm{Kh}$. Ibragimov Complex Institute, RAS, No. 8, pp. 115-118, 2015. 